\title{
A retrospective cohort study of patients with stomach and liver cancers: the impact of comorbidity and ethnicity on cancer care and outcomes
}

Diana Sarfati ${ }^{*}$, Jason Gurney ${ }^{1}$, James Stanley ${ }^{2}$ and Jonathan Koea ${ }^{3}$

\begin{abstract}
Background: Comorbidity has an adverse impact on cancer survival partly through its negative impact on receipt of curative treatment. Comorbidity is unevenly distributed within populations, with some ethnic and socioeconomic groups having considerably higher burden. The aim of this study was to investigate the inter-relationships between comorbidity, ethnicity, receipt of treatment, and cancer survival among patients with stomach and liver cancer in New Zealand.
\end{abstract}

Methods: Using the New Zealand Cancer Registry, Māori patients diagnosed with stomach and liver cancers were identified $(n=269)$, and compared with a randomly selected group of non-Māori patients $(n=255)$. Clinical and outcome data were collected from medical records, and the administrative hospitalisation and mortality databases. Logistic and Cox regression modelling with multivariable adjustment were used to examine the impacts of ethnicity and comorbidity on receipt of treatment, and the impact of these variables on all-cause and cancer specific survival.

Results: More than $70 \%$ of patients had died by two years post-diagnosis. As comorbidity burden increased among those with Stage I-III disease, the likelihood that the patient would receive curative surgery decreased (e.g. C3 Index score 6 vs 0, adjusted OR: 0.32, 95\% Cl 0.13-0.78) and risk of mortality increased (e.g. C3 Index score 6 vs 0, adjusted all-cause HR: 1.44, 95\% Cl 0.93-2.23). Receipt of curative surgery reduced this excess mortality, in some cases substantially; but the extent to which this occurred varied by level of comorbidity. Māori patients had somewhat higher levels of comorbidity (34\% in highest comorbidity category compared with 23\% for non-Māori) and poorer survival that was not explained by age, sex, site, stage, comorbidity or receipt of curative surgery (adjusted cancer-specific HR: 1.36, 95\% Cl 0.97-1.90; adjusted all-cause HR: 1.33, 95\% Cl 0.97-1.82). Access to healthcare factors accounted for $25-36 \%$ of this survival difference.

Conclusions: Patients with comorbidity were substantially less likely to receive curative surgery and more likely to die than those without comorbidity. Receipt of curative surgery markedly reduced their excess mortality. Despite no discernible difference in likelihood of curative treatment receipt, Māori remained more likely to die than non-Māori even after adjusting for confounding and mediating variables.

Keywords: Comorbidity, Ethnicity, Cancer, Hepatic neoplasms, Gastric neoplasms, Māori, New Zealand, Survival

\footnotetext{
*Correspondence: diana.sarfati@otago.ac.nz

'Department of Public Health, University of Otago Wellington, PO Box 7343,

Wellington 6242, New Zealand

Full list of author information is available at the end of the article
}

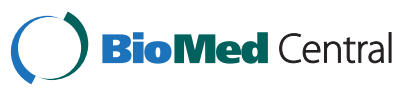

(c) 2014 Sarfati et al.; licensee BioMed Central Ltd. This is an Open Access article distributed under the terms of the Creative Commons Attribution License (http://creativecommons.org/licenses/by/4.0), which permits unrestricted use, distribution, and reproduction in any medium, provided the original work is properly credited. The Creative Commons Public Domain Dedication waiver (http://creativecommons.org/publicdomain/zero/1.0/) applies to the data made available in this article, unless otherwise stated. 


\section{Background}

Patients with cancer often carry the dual burden of the cancer itself and other co-existing chronic conditions. Comorbidity can have a substantial impact on the patient, their clinicians and the health services in general [1-5]. The role of comorbidity in the care and outcomes of cancer patients is complex with the inter-relationships between comorbidity, receipt of treatment and outcomes for cancers poorly understood. The impact of these factors in explaining disparities in cancer survival between patients in different ethnic or socioeconomic groups remains even less clear.

Comorbidity is known to have a negative impact on the likelihood of receiving curative treatment among cancer patients generally [6-14]. For example, a systematic review of studies analysing the use of chemotherapy among stage III colon cancer patients in the US reported that seven out of nine studies found comorbidity had a deleterious effect on chemotherapy receipt [15]. The magnitude of the effect was large with the odds ratios comparing the uptake of chemotherapy among patients with Charlson (global measure of comorbidity) scores of 2 or $3+$ with those with scores of 0 ranging from $0.38-0.44$ in one large study [15]. The impact of comorbidity on treatment for stomach and liver cancers specifically has not been established.

This issue is important because whilst it is clear that those with comorbidity have poorer cancer survival, it is not entirely clear the extent to which this occurs due to the direct effect of comorbidity or through its impact on treatment choice or effectiveness. Intuitively it is likely that both play a part. Few studies have investigated this issue, but those that do suggest that, among cancer patients, at least part of the excess mortality among those with comorbidity is due to lower receipt of definitive treatment $[13,14]$.

Comorbidity is common among cancer patients in general, but those in ethnic minority and lower socioeconomic groups frequently carry a greater burden of chronic disease than others [16-19]. These same groups often experience poorer cancer survival [19-22]. Comorbidity has been shown to be in part responsible for these disparities in cancer survival. For example, a study by Hill et al. [20] showed that a third of the disparity in colon cancer survival between Māori (Indigenous New Zealanders) and non-Māori New Zealanders was due to comorbidity. Studies in other countries have similarly found that disparities in cancer survival between indigenous and non-indigenous populations are, at least partially, explained by differences in levels of comorbidity $[19,23]$. In the US, the evidence relating to the impact of comorbidities on ethnic/racial inequalities in outcomes is inconsistent. Several authors have found that comorbidity partially or completely explains such disparities [14,24-29], while others have concluded that comorbidity may not be important in this regard [30-32].
This study aims to investigate the inter-relationships between comorbidity, receipt of treatment, ethnicity and cancer survival among a cohort of patients with liver and stomach cancers in New Zealand. Internationally, stomach and liver cancers are the third- and fourth leading causes of cancer deaths respectively [33].

The specific objectives of this study are to investigate: 1) the impact of comorbidity on receipt of curative treatment; 2) the impact of comorbidity on all-cause and cancer-specific survival, and the proportion of any excess mortality explained by lack of receipt of treatment and 3) the extent to which comorbidity and receipt of definitive treatment explains differences in survival between Māori and non-Māori New Zealanders with liver or stomach cancer.

\section{Methods}

\section{Data sources}

Incident cases of stomach (ICD-10-AM code: C16.x) and hepatocellular (C22.0) cancers diagnosed between 1 Jan 2006 and 31 Dec 2008 were identified from the New Zealand Cancer Registry (NZCR). These cancers were combined because there were insufficient numbers of either alone for this study, and there are similarities between these cancers in that both are associated with chronic infection, smoking and alcohol consumption, so are similarly related to comorbidity; both are treated by upper gastrointestinal surgeons and have surgery as their primary treatment modality, and both are associated with similarly poor survival.

New Zealand has mandatory reporting of all cancers (except non-melanoma skin cancer). Patients were eligible for inclusion if they a) were aged 25 years or older at diagnosis; b) were normally resident in New Zealand; c) had no previous diagnosis of the same primary cancer; and d) were diagnosed prior to their death. New Zealand is divided into two main Islands (North and South), with nearly $80 \%$ of the population (and specifically $90 \%$ of the Māori population) based in the North Island [34]. All eligible Māori patients (who make up 15\% of the total population) residing in the North Island were included, along with an equal number of randomly-sampled nonMãori patients. The purpose of this was to ensure that the study had equal explanatory power for Māori and non-Maori. Ethnicity was classified on the basis of Cancer Registry data which uses an ever-Māori approach, where patients are classified as Māori if they have been identified as Māori on any previous health record. All other patients were classified as non-Māori.

Clinical data relating to each patient were extracted from all relevant public and private hospitals in the North Island by a trained oncology nurse. Data were recorded on a standardised study pro-forma, doubleentered and any discrepancies resolved. Details of this 
process are available elsewhere [35]. Data were also collected from routine administrative hospital records (National Minimum Dataset) for the five years prior to diagnosis (for assessment of comorbidity), and the national mortality collection up to the end of 2010 (providing a minimum of two years of follow-up data for all patients). Approval for this study was granted by the New Zealand Multi-Region Ethics Committee (MEC/10/ 042/EXP), and permission for access to the data given by the Ministry of Health and relevant District Health Boards.

\section{Variables}

Sex, age at diagnosis, and prioritised ethnicity (Māori or non-Māori) were determined from the Cancer Registry. Socioeconomic deprivation and urban/rural classification were determined using the domicile of residence data recorded on the Cancer Registry at time of diagnosis. Deprivation was measured using the NZDep index, a small-area based index calculated using aggregated census data based on residents' socioeconomic characteristics (such as benefit receipt, earning under an income threshold, housing tenure, access to car or phone, etc.) [36]. Higher values of the NZDep index indicate greater deprivation.

The clinical notes review provided data on details of patient's presentation (including a specified list of comorbid conditions present at the time of diagnosis), tumour characteristics (including tumour grade, and stage at diagnosis, classified according to the TNM classification system [37]), and receipt of treatment (including surgery, chemotherapy, radiotherapy and palliative care). Curative surgery was defined as surgical intervention among those with Stage I-III disease for whom the treatment intent was curative.

Comorbidity was measured in two ways. First, the 12 most common comorbid conditions identified in the notes review were included in the analysis. Conditions were treated individually, or as a categorised 'count' to assess the overall burden of comorbidity at diagnosis. Second (and separately), all conditions recorded in the administrative hospitalisation data in the five years prior to diagnosis were identified and used to calculate a C3 comorbidity index score for each patient [38]. The C3 index is a cancer-specific index of comorbidity based on the presence of 42 chronic conditions each of which is weighted to its impact on one-year non-cancer mortality in a cancer cohort [39]. These weights are then summed to arrive at a final comorbidity (C3 Index) score. For descriptive analysis of the study cohort, C3 Index scores were categorised into '0' (C3 Index score $<=0)$, ' 1 ' $(0<$ score $<=1)$, '2' $(1<$ score $<=2)$ and ' 3 ' (score $>2)$ Comorbid conditions that may have been complications of the primary disease or its treatment were only included if they were recorded prior to the date of diagnosis or index date of admission (specifically myocardial infarction, congestive heart failure, pulmonary embolism, anxiety/behavioural disorders, anaemias, hypertension and cardiac arrhythmias). In addition, conditions that may have been indicative of early malignancy were excluded; specifically liver disease and upper gastrointestinal 'comorbidity' were excluded when calculating the C3 index score for patients with liver and stomach cancers, respectively.

\section{Statistical analysis}

Māori, non-Māori and total cohorts were compared for demographic and disease characteristics, patient comorbidity and receipt of definitive treatment. Because all Māori patients were included but only a subset of nonMāori patients, the estimates reported for the total cohort were weighted to the total eligible Māori and non-Māori stomach and liver cancer populations. When reporting estimates stratified by ethnicity, rates were age-standardised to the total New Zealand cancer population (2006-2008) using direct standardisation. These analyses were repeated restricted to those with stage I-III disease only. To assess the association between ethnicity and comorbidity, we fitted a linear regression model with the C3 score as the continuous outcome, in order to estimate a mean difference in C3 score adjusting for age as a continuous predictor using restricted cubic splines (see next paragraph). We assessed two-year all-cause and cancer-specific survival using a Kaplan-Meier approach.

Next, a series of multivariable models were fitted to explore the relationships between comorbidity, ethnicity, treatment and survival. In these models age was treated as a continuous variable, and modelled using restricted cubic splines with knots at the $5^{\text {th }}, 50^{\text {th }}$, and $95^{\text {th }}$ percentiles. Comorbidity was treated in two ways in these models. When comorbidity was the primary independent variable the C3 index score was used, treated as a continuous variable and included using restricted cubic splines with knots at the $5^{\text {th }}, 50^{\text {th }}$, and $95^{\text {th }}$ percentiles [40]. When comorbidity was being treated as a confounding or mediating variable, the $\mathrm{C} 3$ index was included in models (using splines as described above), alongside a continuous comorbidity count from the hospital notes review data.

To assess the extent to which comorbidity and ethnicity impacted on the receipt of definitive treatment, patients with Stage IV cancer were excluded from the analysis (since treatment for these patients is indicated for palliative purposes only). First, a logistic regression model was fitted examining the impact of comorbidity on receipt of definitive treatment. Age (modelled as continuous, with restricted cubic splines), sex (M/F), site 
(liver/stomach), deprivation (treated as a continuous linear predictor, in deciles), rurality (rural/non-rural) and ethnicity (Māori/non-Māori) were all treated as potential confounders because they are common causes of both comorbidity and receipt of treatment (see Additional file 1: Figure S1 for causal diagrams). Stage (categorised I, II, III) was fitted last because comorbidity may impact stage at diagnosis (although the direction and magnitude of this impact is unpredictable) $[41,42]$, and stage in turn has an impact on whether or not definitive treatment can be offered and so could be considered both a confounder and a mediator in this relationship.

Next, we assessed the impact of receipt of definitive treatment on all-cause and cancer-specific survival using Cox proportional hazards regression. For these analyses, age, sex, site, stage, ethnicity, deprivation, rurality and comorbidity (using both measures) were all considered confounders and included in the model (See Additional file 1: Figure S1 for causal diagrams).

We then assessed the impact of comorbidity (C3 Index scores) on survival, and the extent to which this was mediated by receipt of definitive treatment. For these analyses, age, sex, site, ethnicity, deprivation and rurality were considered confounders. Stage of disease was fitted next (for aforementioned reasons), followed by receipt of definitive treatment.

To assess whether ethnicity had an impact on receipt of definitive treatment, and the extent to which this association was mediated by comorbidity, a logistic regression model was fitted. For these models, age, sex and site were considered confounders and were added to the model first, followed by stage. Stage was considered a mediator because ethnicity is likely to impact on stage of diagnosis through factors such as uneven access to primary care services, which in turn impacts on treatment. We were interested in the impact of comorbidity once the effect of stage at diagnosis had been accounted for. Comorbidity was added to the model (using both the $\mathrm{C} 3$ index score and the count of the number of comorbidities) to estimate the extent to which the potential remaining effect of ethnicity on receipt of treatment was caused by differential levels of comorbidity between ethnic groups. Access to healthcare factors (deprivation and rurality) were added last as additional potential mediators in this association.

Finally, to assess the impact of ethnicity and comorbidity on (all-cause and cancer-specific) survival, Cox regression models were fitted following the same sequential model adjustment protocol as outlined above (with the addition of receipt of curative treatment). For all Cox regression models, individuals were censored at the end of follow up time. For cancer-specific analyses, patients were censored at their date of death if they died of non-cancer causes.
All analyses were carried out in SAS v9.2. Those models with exposures fit with restricted cubic spline variables were conducted using an add-in macro [40] which also produces solutions of the odds/hazard ratios at specified points in the exposure distribution.

\section{Results}

There were 269 Māori patients and 255 non-Māori patients (total $n=524$ ) included in this study. Patient characteristics are shown in Table 1. Patients with stomach cancer comprised $64 \%$ of the total cohort. Males formed the majority of the cohort (67\% versus $33 \%$ female). The overall mean age was 64 years $(\mathrm{SD}=15)$, with the Māori cohort having a younger mean age (Māori: 60 years, SD 14; Non-Māori: 68 years, SD 14; $p<0.001)$. A substantial proportion of the cohort was recorded as having latestage disease, with $43 \%$ diagnosed at Stage IV. There were 293 patients with stage I-III disease. The profile for stage of disease at diagnosis was similar for Māori and non-Māori. Māori were considerably more likely to reside in areas of high deprivation than non-Māori (ageadjusted proportion residing in NZDep deciles 9-10, Māori: 60\%, non-Māori: 27\%; $p<0.001$ ). Māori were also less likely to reside in an urban area compared to nonMāori (age-adjusted proportion residing in urban area, Māori: 65\%, non-Māori 83\%; $p<0.001$ ). More than 70\% of all patients in both ethnic groups and for both stomach and liver cancers had died within two years of diagnosis (Table 2). Additional file 1: Table S1 shows patient characteristics for those diagnosed with Stage I to III disease only; with the distribution of characteristics being very similar as for the full cohort.

The distribution of the cohort by comorbidity ('C3 Index') category is shown in Table 1 (and Additional file 1: Table S1), with the range being 0 to 12.8 . Proportionally, the greatest number of patients were recorded as having no comorbidity (C3 Index category '0'; weighted proportion of total cohort: $40 \%$ ), but $28 \%$ in the total cohort had levels of comorbidity in the highest category (C3 index category 3). Age-standardised results suggested that proportionally fewer Māori patients had no comorbidity (age-standardised proportion: Māori 36\%, non-Māori $43 \%$ in the total cohort) and proportionally more had a comorbidity score $>2$ (Māori: 34\%, nonMāori 23\%). Linear regression analysis confirmed that Māori tended to have a higher comorbidity burden than non-Māori (age adjusted mean difference: 0.42, 95\% CI 0.06-0.78). Additional file 1: Table S2 provides the other characteristics of the cohort (site, gender, age, stage, deprivation and rurality) by comorbidity category.

Hypertension was the most common comorbid condition identified from the clinical notes review data (weighted proportion of total cohort: 39\%), with Māori more likely to suffer this condition than non-Māori 
Table 1 Characteristics of the study population: proportions by site sex, age, stage, deprivation, rurality and comorbidity

\begin{tabular}{|c|c|c|c|c|c|c|c|c|c|}
\hline & & & \multicolumn{3}{|c|}{ Māori } & \multicolumn{3}{|c|}{ Non-Māori } & \multirow[b]{3}{*}{$\mathrm{p}$} \\
\hline & \multicolumn{2}{|c|}{ Total cohort $^{1}$} & \multicolumn{2}{|l|}{ Unadj } & \multirow{2}{*}{$\begin{array}{l}\text { Age Std } \\
\%\end{array}$} & \multicolumn{2}{|l|}{ Unadj } & \multirow{2}{*}{$\begin{array}{l}\text { Age Std } \\
\%\end{array}$} & \\
\hline & $\mathrm{n}$ (total $=524)$ & $\%$ & $\mathrm{n}$ (total =269) & $\%$ & & $\mathrm{n}$ (total $=269$ ) & $\%$ & & \\
\hline \multicolumn{10}{|l|}{ Cancer site } \\
\hline Liver cancer & 189 & $36 \%$ & 97 & $36 \%$ & & 92 & $36 \%$ & & \\
\hline Stomach cancer & 335 & $64 \%$ & 172 & $64 \%$ & & 163 & $64 \%$ & & \\
\hline Sex & & & & & & & & & 0.104 \\
\hline Male & 349 & $67 \%$ & 170 & $63 \%$ & $64 \%$ & 179 & $70 \%$ & $70 \%$ & \\
\hline Female & 175 & $33 \%$ & 99 & $37 \%$ & $36 \%$ & 76 & $30 \%$ & $30 \%$ & \\
\hline \multicolumn{10}{|l|}{ Age (years) } \\
\hline $25-49$ & 105 & $20 \%$ & 73 & $27 \%$ & - & 32 & $13 \%$ & - & \\
\hline $50-64$ & 152 & $29 \%$ & 96 & $36 \%$ & - & 56 & $22 \%$ & - & \\
\hline $65-74$ & 139 & $27 \%$ & 64 & $24 \%$ & - & 75 & $29 \%$ & - & \\
\hline $75+$ & 128 & $24 \%$ & 36 & $13 \%$ & - & 92 & $36 \%$ & - & \\
\hline Mean age (SD) & $64(15)$ & & $60(14)$ & & & $68(14)$ & & & $<0.001$ \\
\hline Stage (TNM) & & & & & & & & & 0.688 \\
\hline 1 & 84 & $16 \%$ & 41 & $15 \%$ & $16 \%$ & 43 & $17 \%$ & $17 \%$ & \\
\hline$\|$ & 93 & $18 \%$ & 51 & $19 \%$ & $19 \%$ & 42 & $16 \%$ & $17 \%$ & \\
\hline III & 116 & $22 \%$ & 59 & $22 \%$ & $22 \%$ & 57 & $22 \%$ & $22 \%$ & \\
\hline N & 226 & $43 \%$ & 118 & $44 \%$ & $42 \%$ & 108 & $42 \%$ & $43 \%$ & \\
\hline Unstaged & 5 & $1 \%$ & 0 & - & - & 5 & $2 \%$ & $2 \%$ & \\
\hline NZDep (Deciles) & & & & & & & & & $<0.001$ \\
\hline Lowest deprivation: 1-2 & 38 & $7 \%$ & 12 & $5 \%$ & $5 \%$ & 26 & $10 \%$ & $10 \%$ & \\
\hline $3-4$ & 61 & $12 \%$ & 18 & $7 \%$ & $7 \%$ & 43 & $17 \%$ & $17 \%$ & \\
\hline $5-6$ & 81 & $16 \%$ & 32 & $12 \%$ & $11 \%$ & 49 & $20 \%$ & $19 \%$ & \\
\hline $7-8$ & 112 & $22 \%$ & 47 & $18 \%$ & $18 \%$ & 65 & $26 \%$ & $27 \%$ & \\
\hline Highest deprivation: 9-10 & 217 & $43 \%$ & 151 & $58 \%$ & $60 \%$ & 66 & $27 \%$ & $27 \%$ & \\
\hline Rurality & & & & & & & & & $<0.001$ \\
\hline Urban & 371 & $73 \%$ & 166 & $64 \%$ & $65 \%$ & 205 & $82 \%$ & $83 \%$ & \\
\hline Independent urban & 77 & $15 \%$ & 51 & $20 \%$ & $19 \%$ & 26 & $10 \%$ & $10 \%$ & \\
\hline Rural & 61 & $12 \%$ & 43 & $17 \%$ & $16 \%$ & 18 & $7 \%$ & $7 \%$ & \\
\hline \multicolumn{10}{|l|}{ Common comorbidities } \\
\hline Angina & 78 & $16 \%$ & 36 & $13 \%$ & $17 \%$ & 42 & $16 \%$ & $14 \%$ & 0.376 \\
\hline Hypertension & 200 & $39 \%$ & 106 & $39 \%$ & $46 \%$ & 94 & $37 \%$ & $33 \%$ & $<0.001$ \\
\hline Myocardial infarction & 41 & $9 \%$ & 16 & $6 \%$ & $7 \%$ & 25 & $10 \%$ & $8 \%$ & 0.735 \\
\hline Arrhythmia & 84 & $17 \%$ & 38 & $14 \%$ & $18 \%$ & 46 & $18 \%$ & $16 \%$ & 0.545 \\
\hline $\mathrm{CHF}$ & 51 & $9 \%$ & 29 & $11 \%$ & $15 \%$ & 22 & $9 \%$ & $7 \%$ & $<0.001$ \\
\hline Mild CPD & 32 & $6 \%$ & 17 & $6 \%$ & $7 \%$ & 15 & $6 \%$ & $5 \%$ & 0.385 \\
\hline Mod/Severe CPD & 41 & $9 \%$ & 16 & $6 \%$ & $8 \%$ & 25 & $10 \%$ & $8 \%$ & 0.818 \\
\hline$C V D$ & 53 & $12 \%$ & 19 & $7 \%$ & $9 \%$ & 34 & $13 \%$ & $11 \%$ & 0.418 \\
\hline Uncomplicated diabetes & 131 & $23 \%$ & 74 & $28 \%$ & $29 \%$ & 57 & $22 \%$ & $22 \%$ & 0.100 \\
\hline Other primary tumour & 48 & $10 \%$ & 19 & $7 \%$ & $8 \%$ & 29 & $11 \%$ & $10 \%$ & 0.595 \\
\hline Mod/severe renal disease & 27 & $4 \%$ & 19 & $7 \%$ & $9 \%$ & 8 & $3 \%$ & $3 \%$ & $<0.001$ \\
\hline Obesity & 45 & $7 \%$ & 31 & $12 \%$ & $10 \%$ & 14 & $5 \%$ & $5 \%$ & 0.028 \\
\hline
\end{tabular}


Table 1 Characteristics of the study population: proportions by site sex, age, stage, deprivation, rurality and comorbidity (Continued)

\begin{tabular}{lllllllll}
\hline C3 Index category $^{\mathbf{3}}$ & & & & & & \\
0 & 212 & $40 \%$ & 108 & $40 \%$ & $36 \%$ & 104 & $41 \%$ & $43 \%$ \\
1 & 92 & $18 \%$ & 47 & $17 \%$ & $17 \%$ & 45 & $18 \%$ & $19 \%$ \\
2 & 74 & $14 \%$ & 35 & $13 \%$ & $13 \%$ & 39 & $15 \%$ & $15 \%$ \\
3 & 146 & $28 \%$ & 79 & $29 \%$ & $34 \%$ & 67 & $26 \%$ & $23 \%$ \\
\hline
\end{tabular}

${ }^{1}$ Total cohort results weighted to total liver/stomach cancer population (2006-2008). ${ }^{2}$ Age standardised to total NZ cancer population (2006-2008). ${ }^{3}$ C3 index category: ' 0 ' (C3 Index score $<=0)$, ' 1 ' $(0<$ score $<=1)$, ' 2 ' $(1<$ score $<=2)$ and ' 3 ' (score $>2)$.

(age-standardised proportions: Māori: 46\%, non-Māori $33 \%$; p <0.01). Uncomplicated diabetes $(23 \%)$, arrhythmia (17\%) and angina (16\%) were also common. Māori were more likely to be reported as having congestive heart failure (age-standardised proportion: Māori: 15\%, non-Māori $7 \%$, p <0.01), moderate/severe renal disease (Māori 9\%, non-Māori: 3\%; p <0.01) and obesity (Māori: 10\%, nonMāori: 5\%; $\mathrm{p}=0.03$ ) than non-Maori.

The likelihood of receiving curative treatment reduced in a linear manner with increasing comorbidity (Table 3). For example, those with a C3 Index score of 6 had substantially reduced odds of receipt of curative surgery compared to a C3 Index score of 0, even after adjusting for age, sex, site of cancer, stage of disease, ethnicity, deprivation and rurality (adjusted OR: 0.32, 95\% CI 0.13-0.78).

Receipt of curative surgery was strongly associated with mortality. Those Stage I-III patients who did not receive surgery were three and a half times more likely to die than those who received surgery (cancer-specific $\mathrm{HR}=3.68$, 95\% CI 2.49-5.45; all-cause $\mathrm{HR}=3.54,95 \% \mathrm{CI}$ 2.33-5.34; both models adjusted for age, sex, site, stage, ethnicity, deprivation, rurality and comorbidity).

There was an association between comorbidity and cancer survival but this was non-linear among those with stage I-III disease after adjusting for age, sex, site, stage, ethnicity, deprivation and rurality (Table 4). For example, while a C3 Index score of 3 was associated with a 54-62\% increased likelihood of death compared to those with a score of 0 (adjusted HRs: cancer-specific 1.62, 95\% CI 1.03-2.54; all-cause 1.54, 95\% CI 1.01-2.35), there tended to be a drop-off in risk of mortality beyond this point (e.g. C3 index score 6 vs 0, cancer-specific HR: 1.15, 95\% CI 0.71-1.87; all-cause HR: 1.44, 95\% CI 0.93-2.23).

The introduction of receipt of curative surgery into the models substantially reduced excess mortality among those with comorbidity; for example, the adjusted excess mortality among those with a C3 Index score of 3 (compared to 0) was reduced by almost half, once treatment receipt was included in the model (reduction in excess mortality: cancer-specific $45 \%$; all-cause $48 \%$; treatmentadjusted HRs: cancer-specific 1.34, 95\% CI 0.84-2.13; all-cause HR 1.28, 95\% CI 0.83-1.99;).

On examining ethnic differences in treatment receipt and survival (Table 5), Māori and non-Māori patients had similar odds of curative surgery after adjusting for age, sex, site, stage and comorbidity (adjusted odds ratio [OR]: non-Māori referent; Māori 1.07, 95\% CI 0.57-1.99). Māori appeared more likely to die than non-Māori after adjusting for age, sex, site, stage of disease, comorbidity and receipt

Table 2 Crude all-cause and cancer-specific 2-year survival by cancer site, including median survival time in months

\begin{tabular}{|c|c|c|c|c|c|}
\hline & \multirow[b]{2}{*}{ n (total) } & \multicolumn{2}{|c|}{ All-cause survival } & \multicolumn{2}{|c|}{ Cancer-specific survival } \\
\hline & & $\%$ surviving at 2 years & Median (months) & $\%$ surviving at 2 years & Median (months) \\
\hline \multicolumn{6}{|l|}{ Combined } \\
\hline Total & 524 & $27 \%$ & 8.4 & $29 \%$ & 8.9 \\
\hline Māori & 269 & $26 \%$ & 8.4 & $28 \%$ & 8.6 \\
\hline Non-Māori & 255 & $29 \%$ & 8.8 & $31 \%$ & 9.0 \\
\hline \multicolumn{6}{|l|}{ Liver } \\
\hline Total & 189 & $29 \%$ & 6.6 & $30 \%$ & 7.5 \\
\hline Māori & 97 & $26 \%$ & 6.6 & $27 \%$ & 7.5 \\
\hline Non-Māori & 92 & $32 \%$ & 6.6 & $33 \%$ & 8.0 \\
\hline \multicolumn{6}{|l|}{ Stomach } \\
\hline Total & 335 & $27 \%$ & 9.0 & $29 \%$ & 9.5 \\
\hline Māori & 172 & $26 \%$ & 8.9 & $28 \%$ & 9.7 \\
\hline Non-Māori & 163 & $27 \%$ & 9.0 & $30 \%$ & 9.3 \\
\hline
\end{tabular}


Table 3 Association between comorbidity and treatment receipt among stage I-III patients: unadjusted and adjusted odds ratios

\begin{tabular}{clll}
\hline Impact of comorbidity evaluated at C3 score of:* & Unadjusted OR (95\% Cl) & Adj OR ** (95\% Cl) \\
\hline 0 & 1.00 & 1.00 \\
1 & $0.70(0.50-0.98)$ & $0.92(0.59-1.42)$ \\
2 & $0.53(0.31-0.89)$ & $0.80(0.40-1.6)$ \\
3 & $0.42(0.23-0.78)$ & $0.66(0.29-1.49)$ \\
6 & $0.29(0.15-0.56)$ & $0.32(0.13-0.78)$
\end{tabular}

* evaluation of the OR at a score of 1, 2, 3 and 6 (in relation to a score of 0 ). No results are presented beyond 6 as the $95^{\text {th }}$ percentile of the C 3 Index score distribution was 6.74 , which means estimates of the OR beyond this point on the scale are of limited utility.

** adjusted for age (continuous), sex, site (stomach/ liver), stage (I, II, III), deprivation (continuous, in deciles), rurality (rural/other), ethnicity (Māori/ Non-Māori).

of treatment, with an estimated 33-36\% higher mortality; although confidence intervals around these estimates included the null (adjusted HRs: cancer-specific 1.36, 95\% CI 0.97-1.90; all-cause 1.33, 95\% CI 0.97-1.82). Additionally adjusting for access to healthcare factors (deprivation and rurality) accounted for $25 \%$ of the remaining excess cancer-specific and $36 \%$ of the excess all-cause mortality.

\section{Discussion}

In a cohort of patients with liver and stomach cancers, increasing levels of comorbidity were associated with a reducing likelihood of receipt of definitive treatment. Receipt of definitive treatment was, in turn, strongly associated with survival. Comorbidity was also associated with poorer cancer-specific and all-cause survival, although the association levelled off for those with the highest comorbidity scores. Receipt of curative surgery substantially reduced excess mortality among those with comorbidity, the extent of which varied non-linearly by level of comorbidity. Māori patients were about a third more likely to die from their cancer or all-causes, after adjusting for age, sex, site and stage of disease, but this was largely not explained by comorbidity or receipt of definitive treatment. Access to healthcare factors accounted for a quarter of cancer-specific and a third of all-cause survival difference.

The high prevalence of comorbidity among this group of patients with stomach and liver cancers was expected given the risk profile of these cancers which includes smoking, alcohol and obesity as well as chronic infection [43]. Research has clearly established that cancer patients who also have other chronic conditions are less likely to receive definitive treatment for their cancer, although evidence relating to liver and stomach cancers specifically is sparse [6-14]. Vignette-based studies that ask clinicians to consider decisions on the basis of summarised information about hypothetical patients have also consistently found that surgeons and oncologists are less likely to refer or recommend treatment for cancer patients with comorbidity [44-46].

Intuitively, it is not unreasonable for clinicians (and their patients) to be concerned about the potential for

Table 4 Cancer-specific and all-cause survival by category of comorbidity among those with Stage I-III disease

\begin{tabular}{|c|c|c|c|}
\hline \multirow[b]{2}{*}{ Impact of comorbidity evaluated at C3 Score of:* } & \multicolumn{3}{|c|}{ Cancer-specific mortality Hazard Ratios (95\% CI) } \\
\hline & Unadjusted & Model $1^{1}$ & Model $2^{2}$ \\
\hline 0 & 1.00 & 1.00 & 1.00 \\
\hline 1 & $1.38(1.11-1.71)$ & $1.33(1.04-1.71)$ & $1.24(0.96-1.6)$ \\
\hline 2 & $1.68(1.2-2.36)$ & $1.56(1.05-2.31)$ & $1.36(0.91-2.04)$ \\
\hline 3 & $1.86(1.26-2.74)$ & $1.62(1.03-2.54)$ & $1.34(0.84-2.13)$ \\
\hline \multirow[t]{2}{*}{6} & $1.68(1.08-2.61)$ & $1.15(0.71-1.87)$ & $0.85(0.51-1.4)$ \\
\hline & \multicolumn{3}{|c|}{ All-cause mortality Hazard Ratios $(95 \% \mathrm{CI})$} \\
\hline C3 score sc $^{*}$ & Unadjusted & Model $1^{1}$ & Model $2^{2}$ \\
\hline 0 & 1.00 & 1.00 & 1.00 \\
\hline 1 & $1.30(1.06-1.6)$ & $1.25(0.99-1.58)$ & $1.17(0.92-1.48)$ \\
\hline 2 & $1.57(1.14-2.17)$ & $1.43(0.99-2.07)$ & $1.27(0.87-1.85)$ \\
\hline 3 & $1.77(1.23-2.56)$ & $1.54(1.01-2.35)$ & $1.28(0.83-1.99)$ \\
\hline 6 & $1.97(1.33-2.9)$ & $1.44(0.93-2.23)$ & $1.04(0.66-1.63)$ \\
\hline
\end{tabular}

${ }^{1}$ Adjusted for age, sex, site, stage, ethnicity, deprivation and rurality ${ }^{2}$ Adjusted for all previous variables plus receipt of treatment. ${ }^{*}$ evaluation of the OR at a score of 1, 2, 3 and 6 (in relation to a score of 0 ). No results are presented beyond 6 as the $95^{\text {th }}$ percentile of the C 3 Index score distribution was 6.74 , which means estimates of the OR beyond this point on the scale are of limited utility. 
Table 5 Comparison of Mãori compared with non-Māori patients (Stage I-III): receipt of definitive treatment and excess mortality

\begin{tabular}{|c|c|c|c|}
\hline & $\begin{array}{l}\text { Receipt of definitive treatment } \\
\text { OR }(95 \% \mathrm{Cl})\end{array}$ & $\begin{array}{l}\text { Cancer-specific } \\
\text { HR }(95 \% \mathrm{Cl})\end{array}$ & $\begin{array}{l}\text { All-cause } \\
\text { HR }(95 \% \mathrm{Cl})\end{array}$ \\
\hline Crude & $1.26(0.79-2.02)$ & $1.03(0.76-1.4)$ & $1.01(0.76-1.35)$ \\
\hline+ age, sex and site & $0.9(0.51-1.61)$ & $1.28(0.92-1.76)$ & $1.25(0.92-1.70)$ \\
\hline+ stage & $0.9(0.49-1.63)$ & $1.33(0.96-1.85)$ & $1.29(0.95-1.76)$ \\
\hline + comorbidity* & $1.07(0.57-1.99)$ & $1.23(0.88-1.72)$ & $1.23(0.89-1.69)$ \\
\hline+ treatment receipt & - & $1.36(0.97-1.90)$ & $1.33(0.97-1.82)$ \\
\hline+ health service access factors** & $1.12(0.54-2.35)$ & $1.27(0.88-1.85)$ & $1.21(0.85-1.72)$ \\
\hline
\end{tabular}

${ }^{*}$ Adjusted for both comorbidity count and C3 index.

**Adjusted for deprivation (NZDep decile) and rurality.

higher risk of complications or toxicity from cancer treatment among those with comorbidity. However, the evidence among cancer patients relating to the risk of complications from treatment among those with comorbidity is conflicting. While some studies suggest that those with comorbidity are at greater risk of complications $[11,47,48]$, others have reported that there is no or minimal difference in rates of complications between those with and without comorbidity [49-55]. This suggests that the large differences in treatment offer and receipt between these groups with and without comorbidity may not always be justifiable from the point of view of treatment toxicity and complications. Furthermore, as demonstrated by this and other studies, those with comorbidity who receive definitive treatment appear to have improved chance of survival $[13,49,56]$. However, the question of the extent to which treatment (or lack thereof) impacts on survival for those with comorbidity ideally requires randomised controlled trial evidence. Such trials frequently exclude older patients and those with comorbidity are, such that the evidence produced relates to interventions that apply to younger, healthier patients [57-61]. Given the prevalence of comorbidity among cancer patients, it would seem this well-recognised issue needs to be addressed.

Our finding that Māori patients had poorer survival than non-Mãori patients is consistent with research relating to other cancers [20,62-65]. Māori patients differed from non-Māori patients in a number of respects; they were younger at diagnosis (mean age 60 vs. 68 years), had somewhat higher levels of comorbidity ( $34 \%$ vs $23 \%$ in highest category) and were substantially more likely to live in more deprived (60\% vs $27 \%)$ and rural areas (16\% vs $7 \%)$. However, contrary to our expectations, there were no differences between Māori and non-Māori patients in terms of stage at diagnosis or receipt of curative surgery. Comorbidity and treatment receipt were not able to explain the one-third survival difference between Māori and non-Māori patients, although access to health care factors (deprivation and rurality) accounted for some of this disparity. It may be that these variables reflect some aspects of the timeliness or quality of treatment received that was more subtle than could be assessed in this study.

There are some potential limitations of our study. First, it was an observational study, and the decision to offer treatment is likely to be related to a range of variables for which we did not have information - including both patient factors (such as social support) and disease factors (such as tumour size). As such, the receipt (or nonreceipt) of curative surgery is almost certainly a proxy marker for other prognostic indicators. Since these other unmeasured variables may also be related to comorbidity, the observed reduction in excess mortality among those with high comorbidity following the addition of curative surgery receipt to our survival models may be an overestimate. Put another way, those who are selected to receive surgery, even after adjusting for comorbidity, may be those who have a better prognosis and/or are healthier than those who are not selected for surgery. Furthermore, any global measure of comorbidity is, by necessity, a simplification of reality. We were unable to assess whether there were certain comorbid conditions that were more important than others in terms of receipt of treatment or poor outcomes due to the sample size. Because nearly half the patients in this study had stage IV disease at diagnosis, and because both stomach and liver cancers tend to have poor prognosis for all groups of patients, our ability to discriminate between groups of patients may have been limited. This means there was a lack of precision around some of our estimates and resulting wide confidence intervals.

This study has several significant strengths; first, we were able to secure complete TNM staging data for $99 \%$ of our cohort. Second, we collected data on the total eligible Māori stomach and liver cancer population (and an equal-number of randomly-selected non-Māori), meaning that we had equal explanatory power for both Māori and non-Māori patients. Third, we used two measures of comorbidity; one based on data from clinical notes and the other specifically designed and validated for use among cancer populations (liver and stomach cancers 
included) [38]. This approach is likely to have reduced the mismeasurement of the complex construct of patient comorbidity compared with other more general approaches.

\section{Conclusions}

We observed that patients with high comorbidity were a) substantially less likely to receive curative surgery and b) more likely to die than those without comorbidity. Accounting for provision of curative treatment to those with high comorbidity significantly reduced this excess mortality. There was some evidence of an increased comorbidity burden among indigenous Mãori patients, but no evidence of an inequality in receipt of curative surgery. Despite adjusting for age, gender, stage of disease, comorbidity and receipt of curative surgery, indigenous Mãori patients were still one-third more likely to die of cancer-specific or all-causes than non-Māori.

\section{Additional file}

Additional file 1: Figure S1. Direct Acyclic Graphs (DAGS) for key relationships between comorbidity, receipt of treatment, ethnicity and survival among patients with stomach and liver disease. Table S1. Characteristics of the study population (excluding Stage 4 patients): proportions by site sex, age, stage, deprivation, rurality and comorbidity. Table S2. Characteristics of the study population by C3 index category* proportions by site, gender, age, stage, deprivation and rurality.

\section{Competing interests}

The authors declare that they have no competing interests.

\section{Author information}

DS; MBChB, MPH, PhD. Associate Professor. Public health physician and Director of Cancer Control and Screening Research Unit. JG; PhD. Research Fellow, Cancer Control and Screening Research Unit. JS; PhD. Biostatistician, Senior Research Fellow, Biostatistical Group. JK; MBChB, MD. Associate Professor. Upper gastrointestinal surgeon.

\section{Authors' contributions}

DS initiated and led the study design, the data interpretation, and led the drafting and revisions of the paper. JG contributed to the study design, data analysis and interpretation, and draft revisions. JS contributed to the study design, data analysis and interpretation, and draft revisions. JK provided clinical advice, contributed to study design, data interpretation, and draft revisions. All authors read and approved the final manuscript.

\section{Acknowledgments}

The authors would like to acknowledge Virginia Signal who collected the data from the hospital notes, and the Health Research Council of New Zealand for providing funding for this study (grant 10-404).

\section{Author details \\ 'Department of Public Health, University of Otago Wellington, PO Box 7343 Wellington 6242, New Zealand. ${ }^{2}$ University of Otago Wellington, PO Box 7343, Wellington 6242, New Zealand. ${ }^{3}$ Waitemata District Health Board, Takapuna, Auckland, New Zealand.}

Received: 4 July 2014 Accepted: 27 October 2014 Published: 7 November 2014

\section{References}

1. Extermann M: Measurement and impact of comorbidity in older cancer patients. Crit Rev Oncol Hematol 2000, 35(3):181-200.
2. Extermann M: Interaction between comorbidity and cancer. Cancer Control 2007, 14(1):13-22

3. Gijsen R, Hoeymans N, Schellevis FG, Ruwaard D, Satariano WA, van den Bos GA: Causes and consequences of comorbidity: a review. J Clin Epidemiol 2001, 54(7):661-674.

4. Satariano WA, Silliman RA: Comorbidity: implications for research and practice in geriatric oncology. Crit Rev Oncol Hematol 2003, 48(2):239-248.

5. Yancik R, Ershler W, Satariano W, Hazzard W, Cohen HJ, Ferrucci L: Report of the national institute on aging task force on comorbidity. J Gerontol A Biol Sci Med Sci 2007, 62(3):275-280.

6. Blanco JAG, Toste IS, Alvarez RF, Cuadrado GR, Gonzalvez AM, Martin IJG Age, comorbidity, treatment decision and prognosis in lung cancer. Age Ageing 2008, 37(6):715-718.

7. Chen RC, Royce TJ, Extermann M, Reeve BB: Impact of age and comorbidity on treatment and outcomes in elderly cancer patients. Semin Radiat Oncol 2012, 22(4):265-271.

8. Coebergh JWW, Janssen-Heijnen MLG, Razenberg PPA: Prevalence of co-morbidity in newly diagnosed patients with cancer: A population-based study. Crit Rev Oncol Hematol 1998, 27(2):97-100.

9. Koppie TM, Serio AM, Vickers AJ, Vora K, Dalbagni G, Donat SM, Herr HW, Bochner BH: Age-adjusted Charlson comorbidity score is associated with treatment decisions and clinical outcomes for patients undergoing radical cystectomy for bladder cancer. Cancer 2008, 112(11):2384-2392.

10. Lash TL, Thwin SS, Horton NJ, Guadagnoli E, Silliman RA: Multiple informants: a new method to assess breast cancer patients' comorbidity. Am J Epidemiol 2003, 157(3):249-257.

11. Lee L, Cheung WY, Atkinson E, Krzyzanowska MK: Impact of comorbidity on chemotherapy use and outcomes in solid tumors: a systematic review. J Clin Oncol 2011, 29(1):106-117.

12. Newschaffer CJ, Penberthy LT, Desch CE, Retchin SM, Whittemore M: The effect of age and comorbidity in the treatment of elderly women with nonmetastatic breast cancer. Arch Intern Med 1996, 156(1):85-90

13. Sarfati D, Hill S, Blakely T, Robson B, Purdie G, Dennett E, Cormack D, Dew K: The effect of comorbidity on the use of adjuvant chemotherapy and survival from colon cancer: A retrospective cohort study. BMC Cancer 2009, 9:16.

14. Tammemagi C, Nerenz D, Neslund-Dudas C, Feldkamp C, Nathanson D: Comorbidity and survival disparities among black and white patients with breast cancer. JAMA 2005, 294(14):1765-1772.

15. Etzioni DA, El-Khoueiry AB, Beart RW: Rates and predictors of chemotherapy use for stage III colon cancer. Cancer 2008, 113:3279-3289.

16. Barnett K, Mercer SW, Norbury M, Watt G, Wyke S, Guthrie B: Epidemiology of multimorbidity and implications for health care, research, and medical education: a cross-sectional study. Lancet 2012, 380(9836):37-43.

17. Moulton P, McDonald L, Muus K, Knudson A, Wakefield M, Ludtke R: Prevalence of chronic disease among American Indian and Alaska Native elders. University of North Dakota, Centres for Rural Health, School of Medicine and Health Sciences; 2005 (http://ruralhealth.und.edu/projects/ nrcnaa/pdf/chronic_disease1005.pdf).

18. Robson B, Harris R (Eds): Hauora: Maori Standards of Health IV. A study of the years 2000-2005. Wellington: Te Ropu Rangahau Hauora a Eru Pomare; 2007

19. Valery PC, Coory M, Stirling J, Green AC: Cancer diagnosis, treatment, and survival in Indigenous and non-Indigenous Australians: a matched cohort study. Lancet 2006, 367(9525):1842-1848.

20. Hill S, Sarfati D, Blakely T, Purdie G, Chen J, Dennett E, Cormack D, Cunningham R, Dew K, McCreanor T, Kawachi I: Survival disparities in Indigenous and non-Indigenous New Zealanders with colon cancer: the role of patient comorbidity, treatment and health service factors. J Epidemiol Comm Health 2010, 64:117-123.

21. Rachet B, Woods LM, Mitry E, Riga M, Cooper N, Quinn MJ, Steward J, Brenner H, Esteve J, Sullivan R, Coleman MP: Cancer survival in England and Wales at the end of the 20th century. Br J Cancer 2008, 99:S2-S10.

22. Ward E, Jemal A, Cokkinides V, Cardinez C, Ghafoor A, Thun M: Cancer disparities by race/ethnicity and socioeconomic status. CA Cancer $J$ Clin 2004, 54:78-93. 
23. Sheppard AJ, Chiarelli AM, Marrett LD, Singh GK, Cardinez C, Ghafoor A, Thun M: Stage at diagnosis and comorbidity influence breast cancer survival in First Nations women in Ontario, Canada. Cancer Epidemiol Biomarkers Prev 2011, 20(10):2160-2167.

24. Allard JE, Maxwell GL: Race disparities between black and white women in the incidence, treatment, and prognosis of endometrial cancer. Cancer Control 2009, 16(1):53-56.

25. Braithwaite D, Tammemagi CM, Moore DH, Ozanne EM, Hiatt RA, Belkora J, West DW, Satariano WA, Liebman M, Esserman L: Hypertension is an independent predictor of survival disparity between African-American and white breast cancer patients. Int J Cancer 2009, 124(5):1213-1219.

26. Cook LS, Nelson HE, Cockburn M, Olson SH, Muller CY, Wiggins CL: Comorbidities and endometrial cancer survival in Hispanics and non-Hispanic whites. Cancer Causes Control 2013, 24(1):61-69.

27. Holmes L Jr, Chan W, Jiang Z, Ward D, Essien EJ, Du XL: Impact of androgen deprivation therapy on racial/ethnic disparities in the survival of older men treated for locoregional prostate cancer. Cancer Control 2009, 16(2):176-185

28. Putt M, Long JA, Montagnet C, Silber JH, Chang WW, Kaijun L, Schwartz JS, Pollack CE, Wong Y-N, Armstrong K: Racial differences in the impact of comorbidities on survival among elderly men with prostate cancer. Med Care Res Rev 2009, 66(4):409-435.

29. Yang $R$, Cheung MC, Byrne MM, Huang $Y$, Nguyen D, Lally BE, Koniaris LG: Do racial or socioeconomic disparities exist in lung cancer treatment? Cancer 2010, 116(10):2437-2447.

30. Coker AL, Eggleston KS, Du XL, Ramondetta L: Ethnic disparities in cervical cancer survival among Medicare eligible women in a multiethnic population. Int J Gynecol Cancer 2009, 19(1):13-20.

31. Curtis E, Quale C, Haggstrom D, Smith-Bindman R: Racial and ethnic differences in breast cancer survival: how much is explained by screening, tumor severity, biology, treatment, comorbidities, and demographics? Cancer 2008, 112(1):171-180.

32. Hines RB, Shanmugam C, Waterbor JW, McGwin G Jr, Funkhouser E, Coffey CS, Posey J, Manne U: Effect of comorbidity and body mass index on the survival of African-American and Caucasian patients with colon cancer. Cancer 2009, 115(24):5798-5806.

33. Ferlay J, Shin HR, Bray F, Forman D, Mathers C, Parkin DM: Estimates of worldwide burden of cancer in 2008: GLOBOCAN 2008. Int J Cancer 2010, 127(12):2893-2917.

34. Statistics New Zealand: http://www.stats.govt.nz/browse_for_stats/ population/estimates_and_projections/subnational-ethnic-populationprojections/north-and-south-islands.aspx. Secondary http://www.stats.govt. nz/browse_for_stats/population/estimates_and_projections/subnationalethnic-population-projections/north-and-south-islands.aspx Accessed January 2014.

35. Chamberlain J, Sarfati D, Cunningham R, Koea J, Gurney J, Blakely T: Incidence and management of hepatocellular carcinoma among Māori and non-Māori New Zealanders. Aust NZ J Public Health 2013, 37:520-526.

36. Salmond C, Crampton P, Atkinson J: NZDep 2006 Index of Deprivation User's Manual. Wellington: University of Otago; 2007.

37. Edge S, Byrd DR, Compton CC, Fritz AG, Greene FL, Trotti A: AJCC Cancer Staging Manual. 7th edition. New York: Springer; 2010.

38. Sarfati D, Gurney J, Stanley J, Salmond C, Crampton P, Dennett E, Koea J, Pearce N: Cancer-specific administrative data-based comorbidity indices provided valid alternative to Charlson and NHI indices. J Clin Oncol 2014, 67(5):586-595.

39. Sarfati D, Gurney J, Lim B, Bagheri N, Simpson A, Koea J, Dennett E: Identifying important comorbidity among cancer populations using administrative data: prevalence and impact on survival. Asia Pac J Clin Oncol 2013, doi:10.1111/ajco.12130.

40. Desquilbet $L$, Mariotti F: Dose-response analyses using restricted cubic spline functions in public health research. Stat Med 2010, 29(9):1037-1057.

41. Fleming ST, Pursley HG, Newman B, Pavlov D, Chen K: Comorbidity as a predictor of stage of illness for patients with breast cancer. Med Care 2005, 43(2):132-140.

42. Terret C, Castel-Kremer E, Albrand G, Droz JP: Effects of comorbidity on screening and early diagnosis of cancer in elderly people. Lancet Oncol 2009, 10(1):80-87.

43. Adami HO, Hunter D, Trichopoulos D (Eds): Textbook of Cancer Epidemiology. 2nd edition. New York: Oxford University Press; 2008.
44. Keating NL, Landrum MB, Klabunde CN, Fletcher RH, Rogers SO, Doucette WR, Tisnado D, Clauser S, Kahn KL: Adjuvant chemotherapy for stage III colon cancer: do physicians agree about the importance of patient age and comorbidity? J Clin Oncol 2008, 26(15):2532-2537.

45. Krzyzanowska MK, Regan MM, Powell M, Earle CC, Weeks JC: Impact of patient age and comorbidity on surgeon versus oncologist preferences for adjuvant chemotherapy for stage III colon cancer. J Am Coll Surg 2009, 208(2):202-209.

46. Ring A: The influences of age and co-morbidities on treatment decisions for patients with HER2-positive early breast cancer. Crit Rev Oncol Hematol 2010, 76(2):127-132.

47. Hall WH, Jani AB, Ryu JK, Narayan S, Vijayakumar S: The impact of age and comorbidity on survival outcomes and treatment patterns in prostate cancer. Prostate Cancer Prostatic Dis 2005, 8(1):22-30.

48. Rieker RJ, Hammer E, Eisele R, Schmid E, Hogel J: The impact of comorbidity on the overall survival and the cause of death in patients after colorectal cancer resection. Langenbeck Arch Surg 2002, 387(2):72-76.

49. Gronberg BH, Sundstrom S, Kaasa S, Bremnes RM, Flotten O, Amundsen T, Hjelde HH, Plessen C, Jordhoy M: Influence of comorbidity on survival, toxicity and health-related quality of life in patients with advanced non-small-cell lung cancer receiving platinum-doublet chemotherapy. Eur J Cancer 2010, 46(12):2225-2234.

50. Gross CP, McAvay GJ, Guo Z, Tinetti ME: The impact of chronic illnesses on the use and effectiveness of adjuvant chemotherapy for colon cancer. Cancer 2007, 109(12):2410-2419.

51. Lemmens VEPP, Janssen-Heijnen MLG, Houterman S, Verheij KDGW, Martijn $H$, van de Poll-Franse L, Coebergh JWW: Which comorbid conditions predict complications after surgery for colorectal cancer? World J Surg 2007, 31(1):192-199.

52. LoConte NK, Smith M, Alberti D, Bozeman J, Cleary JF, Setala AN, Wodtke G, Wilding G, Holen KD: Amongst eligible patients, age and comorbidity do not predict for dose-limiting toxicity from phase I chemotherapy. Cancer Chemother Pharmacol 2010, 65(4):775-780.

53. Meyerhardt JA, Catalano PJ, Haller DG, Mayer RJ, Macdonald JS, Benson AB 3rd, Fuchs CS: Impact of diabetes mellitus on outcomes in patients with colon cancer. J Clin Oncol 2003, 21(3):433-440.

54. Peters TTA, van der Laan BFAM, Plaat BEC, Wedman J, Langendijk JA, Halmos GB: The impact of comorbidity on treatment-related side effects in older patients with laryngeal cancer. Oral Oncol 2011, 47(1):56-61.

55. Seymour MT, Thompson LC, Wasan HS, Middleton G, Brewster AE, Shepherd SF, O'Mahony MS, Maughan TS, Parmar M, Langley RE, Focus Investigators National Cancer Research Institute Colorectal Cancer Clinical Studies Group: Chemotherapy options in elderly and frail patients with metastatic colorectal cancer (MRC FOCUS2): an open-label, randomised factorial trial. Lancet 2011, 377(9779):1749-1759.

56. Lemmens VE, Janssen-Heijnen ML, Verheij CD, Houterman S, van Driel OJ $\mathrm{R}$, Coebergh JW: Co-morbidity leads to altered treatment and worse survival of elderly patients with colorectal cancer. Br J Surg 2005, 92(5):615-623.

57. Bellera C, Praud D, Petit-Moneger A, McKelvie-Sebileau P, Soubeyran P, Mathoulin-Pelissier S: Barriers to inclusion of older adults in randomised controlled clinical trials on Non-Hodgkin's lymphoma: a systematic review. Cancer Treat Rev 2013, 39(7):812-817.

58. Fortin M, Dionne J, Pinho G, Gignac J, Almirall J, Lapointe L: Randomized controlled trials: do they have external validity for patients with multiple comorbidities? Ann Fam Med 2006, 4(2):104-108.

59. Hutchins LF, Unger JM, Crowley JJ, Coltman CA Jr, Albain KS: Underrepresentation of patients 65 years of age or older in cancer-treatment trials. N Eng J Med 1999, 341(27):2061-2067.

60. Murthy VH, Krumholz HM, Gross CP: Participation in cancer clinical trials: race-, sex-, and age-based disparities. JAMA 2004 291(22):2720-2726

61. Scher KS, Hurria A: Under-representation of older adults in cancer registration trials: known problem, little progress. J Clin Oncol 2012, 30(17):2036-2038.

62. Brewer N, Borman B, Sarfati D, Jeffreys M, Fleming ST, Cheng S, Pearce N: Does comorbidity explain the ethnic inequalities in cervical cancer survival in New Zealand? A retrospective cohort study. BMC Cancer 2011, 11:132. 
63. Hill S, Sarfati D, Blakely T, Robson B, Purdie G, Dennett E, Cormack D, Dew K, Ayanian JZ, Kawachi I: Ethnic disparities in treatment of Mãori and non-Māori New Zealanders with colon cancer. Cancer 2010, 116:3205-3214.

64. Jeffreys M, Stevanovic S, Tobias M, Lewis C, Ellison-Loschmann L, Pearce N, Blakely T: Ethnic differences in cancer survival in New Zealand: linkage study. Am J Public Health 2005, 95(5):834-837.

65. Stevens W, Stevens G, Kolbe J, Cox B: Ethnic differences in the management of lung cancer in New Zealand. J Thorac Oncol 2008, 3(3):237-244.

doi:10.1186/1471-2407-14-821

Cite this article as: Sarfati et al:: A retrospective cohort study of patients with stomach and liver cancers: the impact of comorbidity and ethnicity on cancer care and outcomes. BMC Cancer 2014 14:821.

\section{Submit your next manuscript to BioMed Central and take full advantage of:}

- Convenient online submission

- Thorough peer review

- No space constraints or color figure charges

- Immediate publication on acceptance

- Inclusion in PubMed, CAS, Scopus and Google Scholar

- Research which is freely available for redistribution 